\title{
Analysis of the African Swine Fever Virus Immunomodulatory Proteins
}

\author{
M. V. Nefedeva ${ }^{a, *}$, I. A. Titov ${ }^{a, * *}$, K. A. Mima ${ }^{a, * * *}$, and A. S. Malogolovkin ${ }^{a, * * * *}$ \\ ${ }^{a}$ Molecular Virology Laboratory Federal Research Center for Virology and Microbiology, \\ Volginsky, Vladimir oblast, 601125 Russia \\ *e-mail:masha67111@mail.ru \\ **e-mail: titoffia@yandex.ru \\ ***e-mail:mima89@ya.ru \\ ****e-mail: Malogolovkin@inbox.ru
}

Received March 29, 2018; revised June 6, 2018; accepted September 7, 2018

\begin{abstract}
Molecular epidemiology of viral infections traditionally based on the analysis of changes in individual genes or genetic markers. The analysis of the African swine fever virus (ASFV) genes encoding immunomodulatory proteins is an important tool for studying the diversity and evolution of the virus. In this work, we carried out a structural and phylogenetic analysis of the ASF virus immunomodulatory proteins 5EL (A238L gene), I14L ( $D p 71 L$ gene), K11L (I329L gene). The degree of nucleotide substitutions of the ASFV concatenated genes $A 238 L, I 329 L$ and $D p 71 L$ revealed purifying (stabilizing) selection at the nucleotide sequences level. The variability characteristic of the selected group of ASFV genes is of great interest for the genetic differences search in immunomodulatory proteins. The sequencing results of the $A 238 L, I 329 L$ and $D p 71 L$ genes and their phylogenetic analysis showed that these genes are conservative among a large group of ASFV genes. The I329L gene is a genetic marker of common origin. The East African strains (Genotype X) of $D p 71 \mathrm{~L}$ gene have two forms: a long (184 amino acids) and a short (from 70 to 72 amino acids) and is formed by fusion of the 13L and 14L. All ASF virus Russian isolates isolated in 2016-2017 were identical to the reference strain ASFV/Georgia/wb/2007. Characterization of variability 5EL protein, I14L, K11L may be serve to identify target sites in the ASFV genome and to develop vaccines. The obtained data allow to evaluate the genetic diversity of the ASFV immunomodulatory proteins and the dynamics of their evolution, to predict the possible participation of the $A 238 L, I 329 L$ and $D p 71 L$ genes in the virulence of various ASFV strains.
\end{abstract}

Keywords: African swine fever virus, sequencing, phylogenetic analysis, immunomodulating proteins, analysis of synonymous and nonsynonymous substitutions

DOI: $10.3103 / \mathrm{S} 0891416819010075$

\section{INTRODUCTION}

African swine fever (ASF) is a hemorrhagic deadly disease of domestic pigs and boars caused by the complex shell deoxivirus of the Asfarviridae family. Mortality in infected herds reaches $100 \%$. The disease is transmitted from sick animals and virus carriers by alimentary, contact and transplacental [1]. The ASFV genome is a linear double-stranded DNA molecule with covalently closed ends and terminal inverted repeats (TIR) [2].

Domestic pigs of all age groups and breeds and wild boars are susceptible to the ASFV. Among the African members of the Suidae family, wild African and bush pigs, warthogs, may be infected with ASFV but without showing clinical signs. The main virus reservoir in the wild in East African countries are soft mites of the genus Ornithodoros [3].
Depending on the virus strain, virulence and mode of infection, the observed clinical signs are diverse in a peracute, acute, subacute and chronic forms of infection [4]. The ASF epidemiology is very complex and varies depending on the geographical features of the area and susceptible species of animals (wild boar, domestic pigs, ticks) [3].

Effective means of protection against the ASFV has not yet been developed. Historical attempts to protect animals with inactivated vaccines have either failed or yielded conflicting results. Studies using attenuated vaccines have demonstrated their potential to protect pigs from experimental infection with a homologous virulent virus, but rarely against heterologous viruses [5-7]. The study of antigenic diversity among naturally occurring of ASFV isolates is of great interest for vaccine development [8].

Recent studies indicate that the virus genetic diversity determined by sequencing the major capsid pro- 
tein P72 (B646L gene) is highest in Central and East Africa [3]. The high level of the ASFV genetic variability between different isolates is explained by the difference in the genome size, but most genetic variation is due to changes in the number and sequence of multigenic families members (MGF) located at both ends of the genome, where they limit the left and right variable regions (LVR and RVR, respectively) [9].

The ASFV genome contains a set of genes encoding the proteins responsible for the immune evasion mechanisms. The modulation activity range of viral proteins is very diverse and includes: inhibition of humoral response, interference with interferons, inhibition of cytokines and chemokines, evasion of cytotoxic T lymphocytes (CTLs) and natural killer cells (NKs), and control of the major histocompatibility complex (MHC I and II) function, changes in the effector function of dendritic cells and inhibition of apoptosis [10].

The ASFV is a macrophage-tropic virus and can manipulate both innate and adaptive immune response by modulating macrophages functions. According to L. Dixon et al., several ASFV proteins have been identified which prevent the development of the host's immune defense [11]. These include the $A 238 L$ gene that encodes a $5 \mathrm{EL}$ protein which acts to inhibit transcriptional activation of host immunomodulatory genes, K11L protein (I329L gene) acting as inhibitor of Toll-like receptors signaling pathways and I14L protein ( $D p 71 L$ gene) similar to the herpes simplex virus-encoded virulence factor ICP34.5 which regulates the phosphatase activity of the host cell during infection displacing inhibitory substrates from PP1 host phosphatase and determining the range of sensitive hosts [12-14]. In addition, $A 238 \mathrm{~L}$ inhibits the host calceneurin dependent pathways by directly binding calceneurin phosphatase [14].

However, not all known ASFV isolates have the same immunomodulatory activity [15]. The genetic background of these differences remains unclear. Thus, the detection of genetic markers of evolutionary variability in ASFV immunomodulating proteins will allow to study the ASFV immune evasion mechanisms.

The aim of the study is to conduct a comparative analysis of nucleotide sequences of ASFV A238L, $I 329 L$ and $D p 71 L$ genes involved in immune evasion.

\section{MATERIAL AND METHODS}

At the first stage, the 5EL, K11L and I14L proteins variability was analyzed using the web service Protein Variability Server by Simpson method (http://www.expasy.org/proteomics) [16]. Region for which the values obtained exceeded the threshold value $(0.46)$ were considered variable. SignalP $4.1 \mathrm{web}$ server was used to predict the presence and location of signal peptide cleavage sites in amino acid sequences. (http://www.cbs.dtu.dk/services/SignalP-4.1) [17].
The CCTOP (Constrained Consensus TOPology prediction server) web application provided prediction of the transmembrane protein topology (http://cctop. enzim.ttk.mta.hu) [18].

At the next stage of work, 12 isolates isolated from different regions of the Russian Federation in 2016 and 15 strains belonging to different genotypes $[19,20]$ and serotypes of the ASFV [21] were selected from the State Collection of Microorganisms of the FRCVM. For each seroimmunotype, attenuated and virulent ASFV strains are used as indicated in the Table 1.

Selection of primers for the copies amplification of the $A 238 L, I 329 L$ and $D p 71 L$ genes was carried out by comparing and analyzing the nucleotide sequences of these genes from strains and various ASFV isolates published in the international GenBank database (http://www.ncbi.nlm.nih.gov/) using BioEdit 7.0.1, Oligo 6.0. and the IDT DNA web server (https://eu.idtdna.com/site).

DNA extraction from blood and organ suspension was performed using DNA-sorb-B kit (Interlabservice, Russia) in accordance with the manufacturer's instructions. Thermal cycler T100 (Bio-Rad Laboratories, USA) was used to optimize the temperature regimes of PCR and gene sequences amplification.

Analysis of the reaction products was carried out by electrophoresis in $1.5 \%$ agarose gel and taken into account on ChemiDoc MP (Bio-Rad Laboratories, USA) by detection specific bands in the tracks with test samples relative to the molecular weight marker fragment and the calculated length of the PCR product. PCR products purification from agarose gel was performed by QIAquick Gel Extraction (QIAGEN) and Cleanup-standard (Evrogen, Russia) commercial kit. The sequencing reaction was performed using the Bigdye terminator v3.1 cycle sequencing kit (Applied Biosystems, USA). Genetic Analyzer 3130 sequencer (Applied Biosystems, USA) was used for sequencing.

Multiple alignment of ASFV gene sequences was performed using variants of the ClustalW method and MUSCLE [22]. To construct phylogenetic trees, the maximum likelihood method was used with an additional bootstrap-analysis of 1000 random samples using the Mega 6.0 program [23].

For the analysis of synonymous (synonymous distance, dS) and non-synonymous substitutions (nonsynonymous distance, dN) per site in the $A 238 L, I 329 L$ and $D p 71 L$ genes, as well as the number of potentially synonymous and non-synonymous sites for each codon based on the hypothesis of equal frequencies of all nucleotide substitutions, the SNAP (Synonymous Non-synonymous Analysis Program) software package was used (www.hiv.lanl.gov). 
Table 1. ASFV strains used in the work

\begin{tabular}{|c|c|c|c|c|c|c|c|}
\hline Strain/isolate & Country & Isolated year & $\begin{array}{c}\text { Geno- } \\
\text { type }\end{array}$ & $\begin{array}{c}\text { Seroimmu- } \\
\text { notype }\end{array}$ & A238L & I329L & DP71L \\
\hline Lisbon-57 (L-57) & Portugal & 1957 & I & 1 & MG209277 & MG209292 & MF589625 \\
\hline LK-111 & Portugal & 1978 & I & 1 & MG209278 & MG209293 & MF589627 \\
\hline Kongo-49 (K-49) & Zaire & 1949 & I & 2 & MG209275 & MG209290 & MF589624 \\
\hline KK-262 & Zaire & - & I & 2 & MG209276 & MG209291 & MF589626 \\
\hline France-32 (F-32) & France & 1964 & I & 4 & MG209272 & MG209288 & MF589621 \\
\hline FK-32/135 & France & Passaged from F-32 & I & 4 & MG209273 & MG209289 & MF589622 \\
\hline CKA-2015 & Russia & $\begin{array}{l}\text { Passaged from Stav- } \\
\text { ropol } 01 / 08\end{array}$ & II & 8 & MG010372 & MG209287 & MF589620 \\
\hline Irkutsk-2017 & Russia & 2017 & II & 8 & MG209274 & - & MF589623 \\
\hline Mozambique-78 (M-78) & Mozambique & 1978 & $\mathrm{~V}$ & 3 & MG209279 & MG209294 & MF589628 \\
\hline MK-200 & Mozambique & Passaged from M-78 & $\mathrm{V}$ & 3 & MG209280 & MG209295 & MF589630 \\
\hline TKF & Tanzania & - & $\mathrm{X}$ & 3 & MG209282 & MG209297 & MF589631 \\
\hline TSP-80 & Tanzania & Passaged in 1980 & $\mathrm{X}$ & 5 & MG209285 & MG209300 & MF589634 \\
\hline TSP-80/300 & Tanzania & - & $X$ & 5 & MG209286 & MG209301 & MF589635 \\
\hline TS-7 & Tanzania & Passaged in 1984 & $X$ & 6 & MG209283 & MG209298 & MF589632 \\
\hline TS-7/27-230 & Tanzania & Passaged in 1986 & $X$ & 6 & MG209284 & MG209299 & MF589633 \\
\hline Nanyuki & Kenya & 1960 & & 8 & MG209281 & MG209296 & MF589629 \\
\hline Lipetsk-2016 & Russia & 2016 & II & 8 & - & - & - \\
\hline \multicolumn{8}{|l|}{ Tambov-2016 } \\
\hline \multicolumn{8}{|l|}{ Moscow-2016 } \\
\hline \multicolumn{8}{|l|}{ Penza-2016 } \\
\hline \multicolumn{8}{|l|}{ Pskov-2016 } \\
\hline \multicolumn{8}{|l|}{ Voronezh-2016 } \\
\hline \multicolumn{8}{|l|}{ Arkhangelsk-2016 } \\
\hline \multicolumn{8}{|l|}{ Kursk-2016 } \\
\hline Krasnodar-2016 & & & & & & & \\
\hline
\end{tabular}

\section{RESULTS AND DISCUSSION}

The results of the proteins $5 \mathrm{EL}, \mathrm{I} 14 \mathrm{~L}$ and $\mathrm{K} 11 \mathrm{~L}$ variability analysis of different ASFV strains showed that the 5EL protein has 13 variable sites, some of which are located in the region of $\mathrm{I} \kappa \mathrm{B}-\mathrm{a}$ similar domain consisting of 3 ankyrin repeats (from 87 to 178 amino acids) and C-terminal end of the PxIxITxC/S motif, which binds the catalytic subunit of calcineurin-serintreonin phosphatase (from 200 to 213 amino acids) (Fig. 1). The ankyrin repetitive proteins although absent in most viruses, are also common among poxviruses. Conservative amino acid residues of ankyrins are crucial for folding and protein stability, and are also involved in the attachment of other proteins to different parts of the cell membrane [24].

Analysis of the $114 \mathrm{~L}$ protein shows that this protein is conservative among the different ASFV strains, but has 7 variable sites. All proteins encoded by this gene contain a central region with a highly conserved 56-amino acid domain and a PP1c_bdg motif (from 7 to 57 amino acids in short form and from 123 to 170 amino acids in long form) of the regulatory subunits (15A and $15 \mathrm{~B}$ ) of protein phosphatase 1 , located at the carboxyl end, common to MyD116 and ICP34.5. This conserved C-terminus appears to be the binding region of the catalytic subunit of protein phosphatase-1 (PP1C), which is found in both the herpes simplex virus and in mice and humans [25].

The highly glycosylated $\mathrm{K} 11 \mathrm{~L}$ protein expressed in the cell membrane and on its surface, containing leucine-rich repeats similar to TLR3, is conservative and has no pronounced variability. For him, there are only 8 variable sites, some of which fall into the extracellular topological domain (from 17 to 239 amino acid), as well as the intracellular topological domain (from 261 to 329 amino acid). The transmembrane region of the protein is located at the C-terminus (from 240 to 260 amino acids) (see Fig. 1).

As a result of observations D. Chapman et al. the $5 \mathrm{EL}$ and $\mathrm{I} 14 \mathrm{~L}$ proteins are attributed to variable, in the 

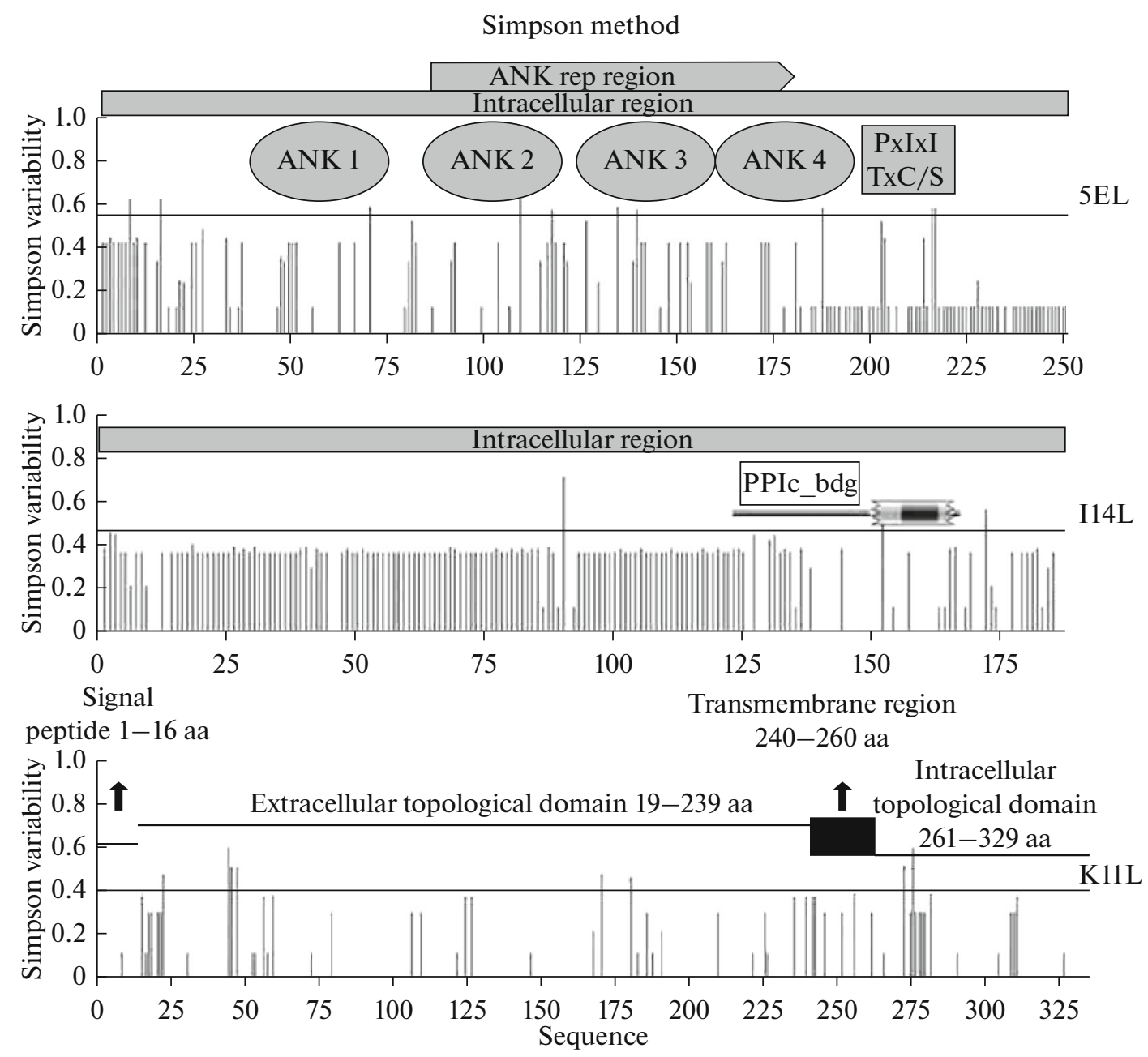

Fig. 1. The results of the variability analysis of proteins 5EL-IkB homolog and inhibitor calceneurin phosphatase; I14L-a protein similar to HSV neurovirulence factor ICP34.5; K11L-a TLR signaling inhibitor protein.

work of V. de Oliveira et al. the K11L protein is conservative, and in the works of J. Neilan et al. and C. Abrams et al., the 5EL protein, on the contrary, was recognized as conservative [12, 26-28]. According to the results of our studies (see Fig. 1), the studied proteins of the ASFV are conservative, especially in comparison with other ASFV variable proteins (CD2V, P54) [29].

In order to determine the genetic relationship at the nucleotide sequences level between ASFV strains and isolates, we performed sequencing and multiple alignment of the concatenated set of $A 238 L, I 329 L$ and Dp $71 L$ genes.

According to the sequencing results of the $A 238 \mathrm{~L}$ and $I 329 \mathrm{~L}$ genes of ASFV isolates, which were isolated on the Russian Federation territory in 2016, are identical to the Georgia_2007/1 parent strain, which is representative of the genotype II.

According to the results obtained for the I329L gene, we can divide the existing isolates into 5 main clusters, which correlate with their genotypes (Fig. 2). The first cluster includes strains from South-East
Africa of genotype V, seroimmunotypes 3 and 7, and full-genome isolates Warthog and Pretorisuskop/96/4 genotypes XIX and XX, seroimmunotype 2 . The second cluster consists of the representatives genotype II seroimmunotype 8 from the Russian Federation. A separate cluster contains strains of genotype I seroimmunotype 2. The fourth cluster consists of strains and isolates of European origin seroimmunotypes 1 and 4, with the exception of isolate Benin 97/1 of African origin belonging to genotype I. The fifth cluster included strains and isolates of genotype $\mathrm{X}$ isolated on the territory of Tanzania and Kenya, as well as some representatives of genotype VIII and IX. Isolates from South Africa and Portugal with indeterminate and seroimmunotype 2 were not included in any of the groups of listed clusters.

An interesting fact is that in 6 East African strains of the genotype X (TKF, Nanyuki, TSP-80, TSP$80 / 300$, TS-7, TS-7/27-230), as in the full-genome isolates Ken05/Tk1, Kenya 1950, Malawi Lil-20/1 and Ken06. Bus strain, the $D p 71 L$ gene is formed by 


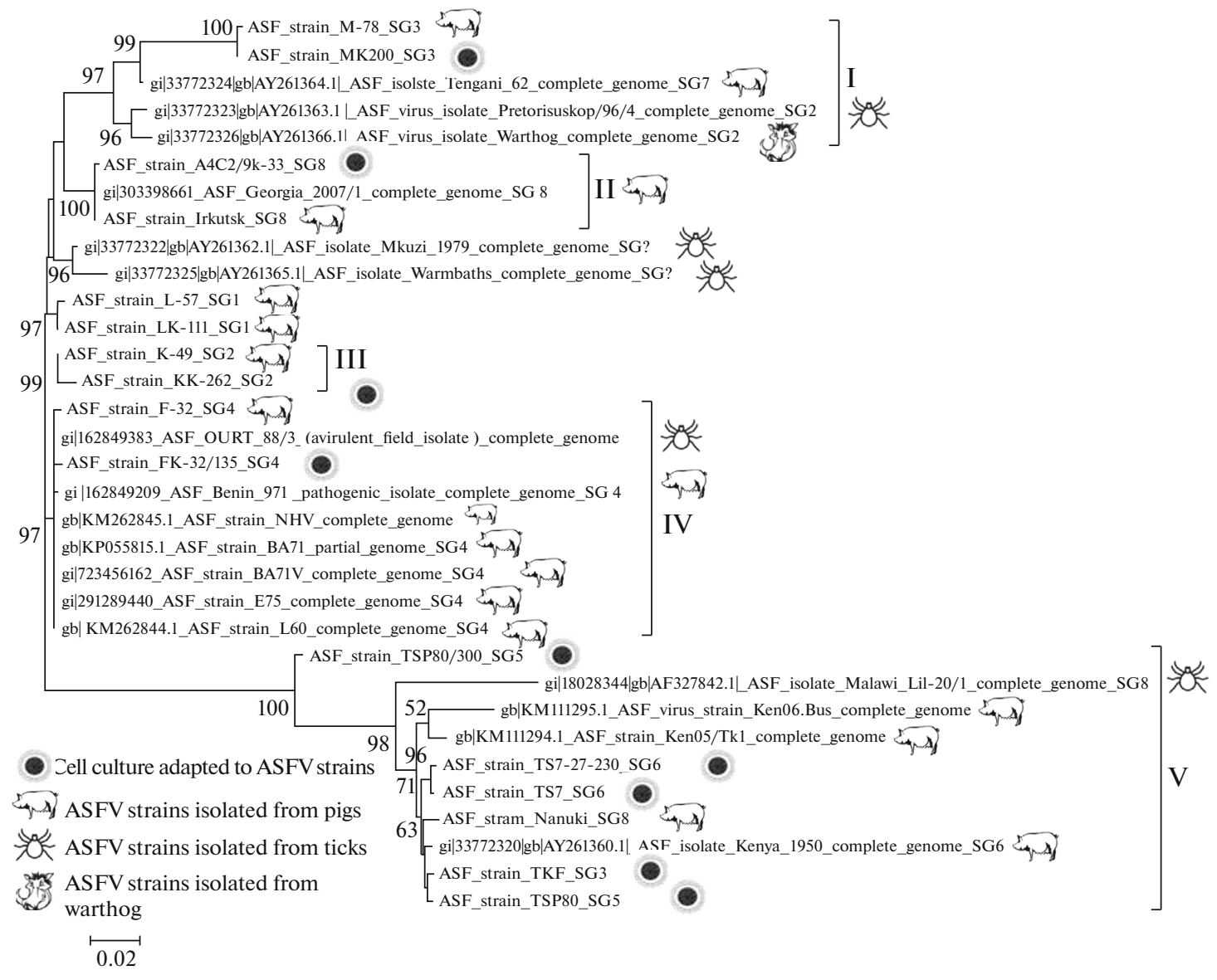

Fig. 2. Phylogenetic dendrogram constructed by the maximum likelihood method based on concatenated nucleotide sequences of ASFV 15 strains of 7 seroimmunotypes. The legend indicates the strains and isolates: -warthogs and 1 -adapted to cell culture.

fusing $13 \mathrm{~L}$ and $14 \mathrm{~L}$. For example, the results of the detection of 2 forms amplification products of the $D p 71 \mathrm{~L}$ gene are shown in Fig. 3. The results of our studies confirm the previously obtained data R. Bishop et al. [30].

Earlier studies have shown that the method of concatenated genes can resolve ambiguities in phylogenetic constructions based on individual genes. The concatenation of large multigene data sets to improve the accuracy of phylogenetic inference is an accepted technique for clusters consisting of orthologous genes [3].

Concatenation is widely used in taxa in which there are complete genomes, for example, in prokaryotes [31] and taxa with small organelle genomes, such as animal mitochondria [32]. The sequence concatenation can hide the main tree of species with different phylogenetic signals in the evolution of individual genes [3].

In our work, the amino acid sequences of three proteins 5EL, K11L, and I14L from 32 ASFV strains were concatenated into one pseudosequence and were used to calculate the ratio of non-synonymous $(\mathrm{dN})-$ synonymous substitution $(\mathrm{dS})$ per site $(\mathrm{dN} / \mathrm{dS}$ ratio).
The number of synonymous substitutions on the synonymous site prevailed over the number of nonsynonymous to a non-synonymous site $0.2788>$ $0.0678(\mathrm{dS}>\mathrm{dN}, \mathrm{pS}>\mathrm{pN})$. When calculating the ratio $\mathrm{dN} / \mathrm{dS}$, the value is $0.2432<1$. This indicates purifying (stabilizing) selection at the level of nucleotide sequences.

Purifying selection occurs most frequently and is characteristic of nucleotide sequences encoding structurally functionally formed proteins. A comparison of the rates of synonymous and nonsynonymous substitutions for ASFV genes revealed from 14 to 18 genes that are subject to positive selection [26]. The role of the immune system in relation to sequence variability can influence the sequences evolution of the ASFV some genes, which therefore can lead to a shift in the time to most recent common ancestor (TMRCA). Lower rates of non-synonymous changes are found in viruses transmitted by arthropod vectors, which reflects the increased cleansing selection pressure associated with replication in various host types. It is 


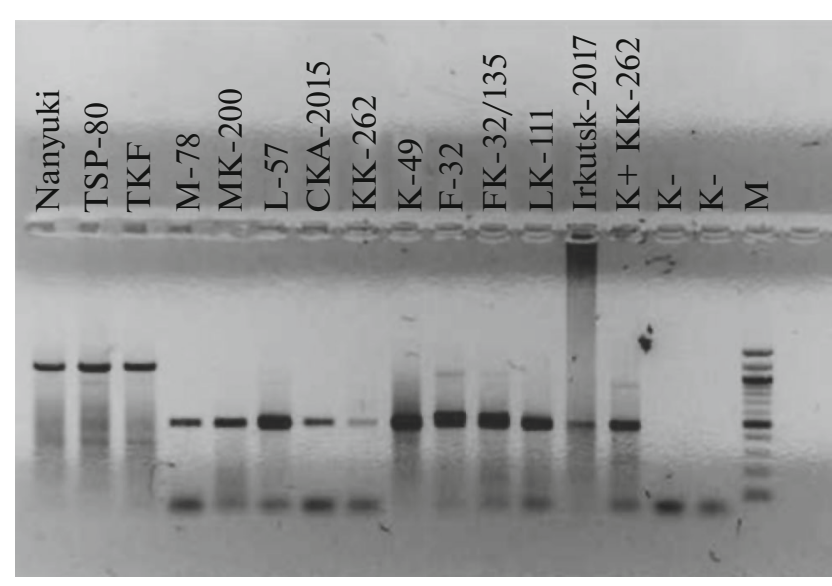

Fig. 3. Electrophoregram of the amplification products of the $D p 71 L$ gene encoding $\mathrm{I} 14 \mathrm{~L}$ protein. $\mathrm{M}=100 \mathrm{~b} . \mathrm{p}$.

possible that many mutations that occur inside the host are removed during transmission between them due to the strong purifying selection, primarily due to the mismatch of the cytotoxic host immune response carried out by T-lymphocytes.

In the work of E. de Villiers et al. 4 models of codon replacement (M1, M2, M7 and M8) were investigated. The M2 model identified 14 ASFV genes under positive selection. These include proteins of the 360 and 505 multigenic families, several hypothetical proteins, a CD2v homologue, several enzymes and viral chaperone $B 602 L$ which ensures the correct folding of the basic protein capsid P72. The strictest model for positive selection M8 identified eighteen genes, eight of which are under positive selection and are genes that can participate in modulating the host cell functions [3].

Data analysis of the ratio of non-synonymous and synonymous mutations at a broad level of the genome show several genes that may be under selective pressure.

\section{CONCLUSIONS}

The range of group variability of proteins was previously studied by various groups of researchers on the example of the P17 proteins [34], P54 and CD2v [15, 26, 33].

Characteristics of the ASFV genes variability of the selected group are object of great interest for searching for genetic differences and markers of evolutionary variability in immunomodulatory proteins and can also serve to identify target sites in the ASFV genome for vaccine development.

The results obtained from bioinformatics analysis showed that the 5EL and I14L proteins have intracellular regions, the K11L protein has extracellular and intracellular topological domains and a transmembrane region. The presence of single nucleotide substitutions in these sites may indicate a greater conservatism of these proteins.
The degree of nucleotide substitutions of the concatenated $A 238 L, I 329 L$ and $D p 71 L$ ASFV genes, as determined in this study, revealed a purifying (stabilizing) selection at the level of the nucleotide sequences. As a result of the nucleotide sequences analysis obtained as a result of sequencing of the $A 238 \mathrm{~L}, I 329 \mathrm{~L}$ and $D p 71 L$ genes, it can be concluded that these genes are conservative, with variable regions within them. All Russian ASFV isolates obtained in 2016-2017 have identical sequences of the $A 238 \mathrm{~L}$ and $I 329 \mathrm{~L}$ genes, which indicate their common origin. The topology of the phylogenetic tree according to the $I 329 \mathrm{~L}$ gene completely corresponds with the phylogenetic tree constructed on the basis of a pseudosequence of 7 immunomodulatory genes. Thus, the $I 329 L$ gene may be a genetic marker of common origin. ASFV I14L protein has two forms: a long one (184 amino acids) and a short one (from 70 to 72 amino acids), which is unique among the ASFV variants.

Using the data obtained, it is possible to predict the possible involvement of these genes in changing the level of virulence inherent in the selected strains, as well as the ability to be factors for the ASFV virulence.

\section{FUNDING}

This work was carried out within the framework of state task and was supported by the Ministry of Science and Higher Education of the Russian Federation. The work was performed as part of the state assignment 0615-2017-0001.

\section{COMPLIANCE WITH ETHICAL STANDARDS}

The authors declare that they have no conflict of interest. This article does not contain any studies involving animals or human participants performed by any of the authors.

\section{AUTHOR CONTRIBUTIONS}

Writing the text, collecting and processing the material, performing individual stages of the experimental part by Nefedeva M.V., gene sequencing by Titov I.A., statistical processing of protein variability by Mima K.A., conception and design of the study, and text editing by Malogolovkin A.S.

\section{REFERENCES}

1. Sanchez-Vizcaino, J.M., African swine fever, in: Diseases of Swine, Straw, B., D'Allaire, S., Mengeling, W., and Taylor, D., Eds., Iowa State Univ., 2006.

2. Rodriguez, J.M., Moreno, L.T., Alejo, A., Lacasta, A., Rodriguez, F., and Salas, M.L., Genome sequence of African swine fever virus BA71, the virulent parental strain of the nonpathogenic and tissue-culture adapted BA71V, PLoS One, 2015, vol. 10, no. 11, p. e0142889. https://doi.org/10.1371/journal.pone.0142889

3. De Villiers, E.P., Gallardo, C., Arias, M., Da Silva, M., Upton, C., Martin, R., et al., Phylogenomic analysis of 11 complete African swine fever virus genome 
sequences, Virology, 2010, vol. 400, pp. 128-136. https://doi.org/10.1016/j.virol.2010.01.019

4. Sanchez-Vizcano, J.M., Mur, L., Gomez-Villamandos, J.C., and Carrasco, J.L., An update on the epidemiology and pathology of African swine fever, J. Comp. Pathol., 2015, vol. 152, pp. 9-21.

https://doi.org/10.1016/j.jcpa.2014.09.003

5. Rock, D.L., Challenges for African swine fever vaccine development-“...perhaps the end of the beginning", Vet. Microbiol., 2017, vol. 206, pp. 52-58.

6. Kolbasov, D.V., Balyshev, V.M., and Sereda, A.D., Overall results of the development of African swine fever live vaccines, Veterinariya, 2014, vol. 8, pp. 3-8.

7. King, K., Chapman, D., Argilaguet, J.M., Fishbourne, E., Hutet, E., Cariolet, R., et al., Protection of european domestic pigs from virulent African isolates of African swine fever virus by experimental immunization, Vaccine, 2011, vol. 29, no. 28, pp. 4593-4600. https://doi.org/10.1159/000170936

8. Dixon, L.K., Abrams, C.C., Chapman, D.D., Goatley, L.C., Netherton, C.L., Taylor, G., et al., Prospects for development of African swine fever virus vaccines, Dev. Biol. (Basel, Switz.), 2013, vol. 135, pp. 147-157. https://doi.org/10.1159/000170936

9. Nix, R.J., Gallardo, C., Hutchings, G., Blanco, E., and Dixon, L.K., Molecular epidemiology of African swine fever virus studied by analysis of four variable genome regions, Arch. Virol., 2006, vol. 151, no. 12, pp. 24752494.

https://doi.org/10.1007/s00705-006-0794-z

10. Dixon, L.K., Baylis, S.A., Vydeingum, S., Twigg, S.R.F., Hammond, J.M., Hingamp, P.M., et al., African swine fever virus genome content and variability, Arch. Virol., 1993, vol. 7, pp. 185-199. https://doi.org/10.1007/978-3-7091-9300-6_15

11. Dixon, L.K., Abrams, C.C., Bowick, G., Goatley, L.C., Kay-Jackson, P.C., Chapman, D., et al., African swine fever virus proteins involved in evading host defense systems, Vet. Immunol. Immunopathol., 2004, vol. 100, nos. $3-4$, pp. $117-134$.

https://doi.org/10.1016/j.vetimm.2004.04.002

12. De Oliveira, V.L., Almeida, S.C., Soares, H.R., Crespo, A., Marshall-Clarke, S., and Parkhouse, R.M.E., A novel TLR3 inhibitor encoded by African swine fever virus (ASFV)., Arch. Virol., 2011, vol. 156, pp. 597609.

https://doi.org/10.1007/s00705-010-0894-7

13. Zsak, L., Lu, Z., Kutish, G.F., Neilan, J.G., and Rock, D.L., An African swine fever virus virulenceassociated gene NL-S with similarity to the herpes simplex virus ICP34.5 gene, J. Virol., 1996, vol. 70, no. 12, pp. 8865-8871.

14. Granja, A.G., Perkins, N.D., and Revilla, Y., A238L inhibits NF-ATc2, NF-kappa B, and c-Jun activation through a novel mechanism involving protein kinase C-theta-mediated up-regulation of the amino-terminal transactivation domain of p300, J. Immunol., 2008, vol. 180, no. 4, pp. 2429-2442.

https://doi.org/10.4049/jimmunol.1490049

15. Chapman, D.A., Tcherepanov, V., Upton, C., and Dixon, L.K., Comparison of the genome sequences of non-pathogenic and pathogenic African swine fever virus isolates, J. Gen. Virol., 2008, vol. 89, no. 2, pp. 397-408.

https://doi.org/10.1099/vir.0.83343-0

16. Garcia-Boronat, M., Diez-Rivero, C.M., Reinherz, E.L., and Reche, P.A., PVS: A web server for protein sequence variability analysis tuned to facilitate conserved epitope discovery, Nucleic Acids Res., 2008, vol. 36, pp. 35-41. https://doi.org/10.1093/nar/gkn211

17. Nielsen, H., Predicting secretory proteins with signal $P$, in Protein Function Prediction, Kihara, D., Ed., Springer, 2017, pp. 59-73. https://doi.org/10.1007/978-1-4939-7015-5_6

18. Dobson, L., Remenyi, I., and Tusnady, G.E., CCTOP: A Consensus Constrained TOPology prediction web server, Nucleic Acids Res., 2015, vol. 43, no. 1 , pp. 408-412. https://doi.org/10.1093/nar/gkv451

19. Gallardo, C., Mwaengo, D.M., Macharia, J.M., Arias, M., Taracha, E.A., Soler, A., et al., Enhanced discrimination of African swine fever virus isolates through nucleotide sequencing of the p54, p72, and pB602L (CVR) genes, Virus Genes, 2009, vol. 38, no. 1, pp. 85-95. https://doi.org/10.1007/s11262-008-0293-2

20. Bastos, A.D., Penrith, M.L., Cruciere, C., Edrich, J.L., Hutchings, G., Roger, F., et al., Genotyping field strains of African swine fever virus by partial p72 gene characterization, Arch. Virol., 2003, vol. 148, no. 4, pp. 693-706. https://doi.org/10.1007/s00705-002-0946-8

21. Sereda, A.D. and Balyshev, V.M., Antigenic diversity of African swine fever viruse, Vopr. Virusol., 2011, vol. 56, no. 4, pp. 38-42.

22. Edgar, R.C., MUSCLE: multiple sequence alignment with high accuracy and high throughput, Nucleic Acids Res., 2004, vol. 32, no. 5, pp. 1792-1797. https://doi.org/10.1093/nar/gkh340

23. Tamura, K., Stecher, G., Peterson, D., Filipski, A., and Kumar, S., MEGA6: Molecular Evolutionary Genetics Analysis version 6.0., Mol. Biol. Evol., 2013, vol. 30 , no. 12 , pp. $2725-2729$. https://doi.org/10.1093/molbev/mst 197

24. Mosavi, L.K., Cammett, T.J., Desrosiers, D.C., and Peng, Z.Y., The ankyrin repeat as molecular architecture for protein recognition, Protein Sci., 2004, vol. 13, no. 6 , pp. $1435-1448$. https://doi.org/10.1110/ps.03554604

25. Jousse, C., Oyadomari, S., Novoa, I., Lu, P.D., Zhang, Y., Harding, H.P., et al., Inhibition of a constitutive translation initiation factor $2 \mathrm{a}$ phosphatase, CReP, promotes survival of stressed cells, J. Cell Biol., 2003, vol. 163, pp. 767-775. https://doi.org/10.1083/jcb.200308075

26. Chapman, D.A., Darby, A.C., Da Silva, M., Upton, C., Radford, A.D., and Dixon, L.K., Genomic analysis of highly virulent Georgia 2007/1 isolate of African swine fever virus, Emerging Infect. Dis., 2011, vol. 17, no. 4, pp. 599-605. https://doi.org/10.3201/eid1704.101283

27. Neilan, J.G., Lu, Z., Kutish, G.F., Zsak, L., Lewis, T.L., and Rock, D.L., A conserved African swine fever virus I kappa B homolog, 5el, is nonessential for growth in 
vitro and virulence in domestic swine, Virology, 1997, vol. 235 , no. 2 , pp. $377-385$.

https://doi.org/10.1006/viro.1997.8693

28. Abrams, C.C., Chapman, D.A., Silk, R., Liverani, E., and Dixon, L.K., Domains involved in calcineurin phosphatase inhibition and nuclear localization in the African swine fever virus A238L protein, Virology, 2008, vol. 374, no. 2, pp. 477-486. https://doi.org/10.1371/journal.pbio.1001492

29. Mima, K.A., Burmakina, G.S., Titov, I.A., and Malogolovkin, A.S., African swine fever virus glycoproteins p54 and CD2v in the context of immune response modulation: Bioinformatic analysis of genetic variability and heterogeneity, $S$-kh. Biol., 2015, vol. 50, no. 6, pp. 785-793.

https://doi.org/10.15389/agrobiology.2015.6.785rus

30. Bishop, R.P., Fleischauer, C., de Villiers, E.P., Okoth, E.A., Arias, M., Gallardo, C., et al., Comparative analysis of the complete genome sequences of Kenyan African swine fever virus isolates within p72 genotypes IX and X, Virus Genes, 2015, vol. 50, no. 2, pp. 303-390.

https://doi.org/10.1007/s11262-014-1156-7
31. Brown, J.R., Douady, C.J., Italia, M.J., Marshall, W.E., and Stanhope, M.J., Universal trees based on large combined protein sequence data sets, Nat. Genet., 2001, vol. 28 , pp. $281-285$. https://doi.org/10.1038/90129

32. Miya, M. and Nishida, M., Use of mitogenomic information in teleostean molecular phylogenetics: A treebased exploration under the maximum-parsimony optimality criterion, Mol. Phylogenet. Evol., 2000, vol. 17 , pp. $437-455$. https://doi.org/10.1006/mpev.2000.0839

33. Rowlands, R.J., Duarte, M.M., Boinas, F., Hutchings, G., and Dixon, L.K., The CD2v protein enhances African swine fever virus replication in the tick vector, Ornithodoros erraticus, Virology, 2009, vol. 393, no. 2, pp. 319-328.

https://doi.org/10.1016/j.virol.2009.07.040

34. Suarez, C., Gutierrez-Berzal, J., Andres, G., Salas, M.L., and Rodriguez, J.M., African swine fever virus protein p17 is essential for the progression of viral membrane precursors toward icosahedral intermediate, J. Virol., 2010, vol. 84, no. 15 , pp. 7484-7499.

https://doi.org/10.1128/JVI.00600-10 